\title{
IDENTIDADE PROFISSIONAL E TRABALHO DOCENTE: O QUE DIZEM OS PROFESSORES DOS CURSOS DE LICENCIATURA DO IFAL
}

\author{
S. S. W. GOMES*; R. M. O. BRASILEIRO E P. R. LIMA \\ Instituto Federal de Alagoas \\ stephanie_weigel@hotmail.com*
}

Artigo submetido em outubro/2014 e aceito em dezembro/2014

DOI: $10.15628 /$ rbept.2014.3496

\section{RESUMO}

O presente trabalho refere-se a uma pesquisa, em andamento, que tem como objetivo refletir sobre a identidade profissional dos professores que atuam nos cursos de licenciatura do Instituto Federal de Alagoas, a partir da sua formação enquanto professor e do trabalho docente desempenhado na instituição de ensino. A abordagem metodológica utilizada é a pesquisa narrativa. A pesquisa está fundamentada pelos estudos de Machado (2008), Lima e Silva (2012), Pimenta e Anastasiou (2002), entre outros. Os sujeitos investigados são os professores efetivos do IFAL - Campus Maceió que atuam nos cursos de licenciatura. Os resultados iniciais da pesquisa possibilitaram iniciar uma reflexão sobre formação continuada para melhoria da prática pedagógica dos professores que atuam nos cursos de licenciatura do IFAL, bem como compreender como se dá o processo de formação da identidade profissional desses docentes, através dos seus relatos por meio de entrevistas.

PALAVRAS-CHAVE: Licenciatura, Formação de Professor, Identidade Profissional.

\section{PROFESSIONAL IDENTITY AND TEACHING JOB: WHAT TEACHERS OF IFAL HAVE TO SAY}

\begin{abstract}
This paper refers to an investigation in progress, which aims to reflect on the professional identity of teachers working in undergraduate courses of the Federal Institute of Alagoas, from their training as teachers and teaching work performed in the institution. The methodological approach is a narrative research. The research is founded by Machado studies (2008), Lima e Silva (2012), Pimenta and Anastasiou (2002), among others. The subjects
\end{abstract}

investigated are effective teachers IFAL - Campus Maceio working in undergraduate courses. Initial results of the survey made it possible to start a reflection on continuing education to improve pedagogical practice of teachers working in IFAL of degree courses as well as understand how is the process of formation of professional identity of these teachers, through their reports through interviews.

KEYWORDS: Degree, Teacher Training, Professional Identity. 


\title{
1 INTRODUÇÃO
}

Abordar discussões a respeito da profissão docente é uma atitude um tanto desafiadora e, ao mesmo tempo, instigante, já que problemáticas que permitem repensar e ressignificar a formação do professor e o processo de ensino e aprendizagem buscando a melhoria da qualidade educacional.

Para realização dessa investigação, a maior inquietação perpassa pela discussão de qual seria a razão da criação dos cursos de licenciatura nos Institutos Federais e qual o perfil adequado do profissional da educação para atuarem nesse nível de ensino.

Os professores, ao ingressarem nos Institutos Federais, devem estar aptos para lecionar em todos os níveis e modalidades de ensino ofertados, desde a educação básica (ensino médio integrado e ensino técnico) até o ensino superior (graduação: cursos tecnológicos, licenciaturas e bacharelados e pós-graduação: cursos de especialização, mestrado e doutorado quando houver), perpassando ainda pelas modalidades de ensino da educação profissional e da educação de jovens e adultos.

Compreendemos que esse professor se torna polivalente, traduzindo uma identidade profissional indefinida.

\begin{abstract}
A polivalência é uma característica do novo modelo de produção, mais flexível e informatizado, que surge para substituir o taylorismo/fordismo. $\mathrm{O}$ aspecto mais relevante deste novo modelo de organização do trabalho é a exigência de o trabalhador desempenhar várias tarefas ou funções dentro do local de trabalho (SANTOS; PIZZI, 2007, p.162).
\end{abstract}

Desta forma, esse professor tem que atender as exigências da sua instituição de ensino, cumprindo com a sua carga horária nos níveis e modalidades de ensino determinados pela sua coordenação, além de desempenhar atividades de pesquisa, extensão e gestão.

Essa situação faz com que o trabalho desse docente não possua uma identidade própria, tendo ele que reorganizar a sua prática educativa para atender a toda essa diversidade educacional, que requer estudos e metodologias próprias para cada nível e modalidade de ensino.

Com base nessa realidade surge a nossa inquietação para realização desta pesquisa. Considerando que a implantação e a ampliação dos Institutos Federais - IFs ocasionaram uma grande crise com relação as suas funções institucionais, no qual os eventos e fóruns relacionados a essa área continuam discutindo a identidade dos IFs, pensamos, nesse trabalho, em investigar a identidade profissional dos professores que atuam nos cursos de licenciatura no Instituto Federal de Alagoas.

A inquietação surge, enquanto pesquisadores, para investigar a identidade dos professores que se dá a partir da seguinte problemática: Qual o perfil profissional dos professores que atuam nos cursos de licenciatura do Instituto Federal de Alagoas?

A partir desta problemática, temos como objetivo refletir sobre a identidade profissional dos professores que atuam nos cursos de licenciatura do Instituto Federal de Alagoas, a partir da sua formação para atuar na área da docência e do trabalho docente desempenhado na instituição de ensino. 


\section{REVISÃO BIBLIOGRÁFICA}

Desde a década de 1980 vivenciamos mudanças estruturais na atividade docente, colocando a figura do professor em papel de destaque no cenário da educação nacional. Muitas políticas vêm focando a formação do professor como fator primordial para o desenvolvimento educacional e a qualidade do ensino.

Ao longo da história da educação brasileira, observamos alguns investimentos em políticas que incentivassem as pessoas a escolherem a profissão de professor. Isso se deve a escassez de docentes, principalmente na área das ciências exatas. Vale ressaltar que esse incentivo por parte do governo, principalmente a partir da década de 1990, tem como fundamento as políticas neoliberais que se consolidaram na área educacional no país.

O fato é que essas iniciativas se tornam contraditórias, uma vez que o mesmo governo que cria tais programas para incentivar a formação de novos docentes, é o mesmo governo que colabora para a desvalorização dos professores, sobrecarregando-os com horas-aula abusivas, salas de aula em condições precárias, baixos salários entre outros. Como resultado, tem-se escolas públicas com grande ausência de professores em todas as regiões do país.

Baseado nessa perspectiva, em 2008 o governo federal a partir da junção entre os CEFETs (Centro Federal de Ciência e Tecnologia) e as Escolas Técnicas, a partir da Lei 11.892, de 29 de dezembro de 2008, cria os Institutos Federais de Educação, Ciência e Tecnologia, onde em seu artigo $2^{\circ}$, estabelece que

\footnotetext{
Os Institutos Federais são instituições de educação superior, básica e profissional, pluricurriculares e multicampi, especializados na oferta de educação profissional e tecnológica nas diferentes modalidades de ensino, com base na conjugação de conhecimentos técnicos e tecnológicos com as suas práticas pedagógicas, nos termos desta Lei.
}

Desta forma, compreende-se que os Institutos Federais ampliaram suas ações, tornandose instituições que ofertam educação básica e ensino superior. Especificamente para a oferta do ensino superior, os Institutos Federais são equiparados as Universidades Federais no que se refere a regulação, avaliação e supervisão das instituições e dos cursos. A seção III da mesma lei trata dos objetivos dos Institutos Federais, no qual destacamos o inciso VI do artigo $7^{\circ}$

VI - ministrar em nível de educação superior:

a) cursos superiores de tecnologia visando à formação de profissionais para os diferentes setores da economia;

b) cursos de licenciatura, bem como programas especiais de formação pedagógica, com vistas na formação de professores para a educação básica, sobretudo nas áreas de ciências e matemática, e para a educação profissional; c) cursos de bacharelado e engenharia, visando à formação de profissionais para os diferentes setores da economia e áreas do conhecimento; d) cursos de pós-graduação lato sensu de aperfeiçoamento e especialização, visando à formação de especialistas nas diferentes áreas do conhecimento; e e) cursos de pós-graduação stricto sensu de mestrado e doutorado, que contribuam para promover o estabelecimento de bases sólidas em educação, ciência e tecnologia, com vistas no processo de geração e inovação tecnológica. 
A partir dessa lei, torna-se função dos Institutos Federais destinar $20 \%$ de suas vagas para oferta de cursos de licenciatura, garantindo a criação e execução de tais cursos. Consideramos que a institucionalização da oferta desses cursos de licenciatura nos Institutos Federais vem reforçar o chamamento do governo para a formação do professor, na tentativa de suprir a carência de pessoal docente qualificado na educação básica.

A grande problemática para esse desafio inclui o questionamento que se é feito em relação aos professores que farão parte da formação dos futuros docentes. Nas demais universidades federais onde até os cursos de licenciatura possuem uma característica de bacharelado e os alunos depois de formados, mesmo com o estágio, não possuem uma ampla noção do que é atuar em sala de aula, acabam por assim formar profissionais despreparados para o mercado de trabalho.

Mesmo considerando a carência de quadro docente, Lima e Silva chamam a atenção para o posicionamento de alguns estudiosos da área sobre a implantação da formação do professor nos IFs.

\begin{abstract}
Segundo Sousa e Beraldo (2009) essas normatizações sobre formação de professores nos IFs representam iniciativas para a solução do problema da escassez de professores, e reconhecem que o desafio imposto a essa nova institucionalidade pode gerar uma crise de identidade de tais instituições, uma vez que elas devem formular projetos educativos para atender alunos de diversas faixas etárias e níveis de ensino. Lembram que o histórico das instituições que compõem a RFEPT está diretamente relacionado à formação de profissionais para áreas técnicas. As experiências na formação de professores são recentes e restritas a algumas instituições. Afirmam ainda que esse quadro tenha implicações no trabalho docente e pode comprometer a qualidade do ensino. (LIMA; SILVA,2011, p.4)
\end{abstract}

A proposta de uma nova matriz curricular eficaz totalmente voltada para uma formação de professor trazida pelos Institutos Federais é considerada desafiadora, pois grande parte do corpo docente é formada por professores que só estão acostumados em formar técnicos, consequentemente preparar os alunos para um mercado de trabalho focado em indústrias, com traços educacionais da Revolução Industrial, quando se ensinava de acordo com a necessidade do mercado. Já como vantagem dos cursos de licenciatura criados nos Institutos Federais, além de ensino superior, há o ensino médio que proporciona um diferencial para o futuro professor, uma vez que o local onde ele estuda serve diariamente como área de observação e prática para o que será seu real campo de atuação, o aproximando da realidade do que é ser professor e das práticas de sala de aula.

Por esse motivo, para que o novo modelo de um curso de licenciatura funcione eficazmente, é necessário que os professores dos Institutos Federais estejam motivados a se prepararem para tal missão, dispostos a conhecer novos tipos de metodologias através de cursos de formação continuada, ficando assim, melhor preparados para ensinar a dar aula.

Mas será que esses professores estão realmente dispostos? O ideal seria que os profissionais ligados às licenciaturas fossem dedicados apenas a formação de professores, para que o curso tenha uma verdadeira identidade e funcione como planejado; mas, será que isso é possível? Os professores dos Institutos Federais que estão em sala de aula no ensino técnico em sua maioria são os mesmos professores que estão também atuando nas licenciaturas. Situação 
essa que acaba gerando uma falta de identidade não só do profissional como também das próprias licenciaturas, onde os maiores afetados serão os candidatos a futuros professores, que continuarão despreparados para atuar dentro de sala de aula como já ocorre nas Universidades Federais.

\section{METODOLOGIA}

Para realização da investigação, optamos pela pesquisa qualitativa, já que esta enfatiza mais o processo do que o produto, se preocupando em retratar a perspectiva dos participantes.

$\mathrm{Na}$ pesquisa qualitativa todas as pessoas que participam da pesquisa são reconhecidas como sujeitos que elaboram conhecimentos e produzem práticas adequadas para intervir nos problemas que identificam. Pressupõem-se, pois, que elas têm um conhecimento prático, de senso comum e representações relativamente elaboradas que formam uma concepção de vida e orientam as suas ações individuais (CHIZZOTTI, 2001, p. 38).

Nesta perspectiva, compreendemos que analisar os dados coletados durante a pesquisa qualitativa significa "trabalhar" com todo material a ser obtido durante a investigação: relatos de observações, respostas de questionários, transcrições de entrevistas, análises de documentos, entre outras informações.

Como abordagem metodológica foi utilizada a pesquisa narrativa, possibilitando o resgate da memória e o relato das vozes dos sujeitos investigados, agregando sentidos e significados ao que está sendo narrado.

Segundo Guedes-Pinto (2002, p. 108), “a narrativa constitui-se, assim, como um instrumento de resistência, do ponto de vista do entrevistado, que pôde trazer possibilidades de um pensar sobre suas ações, inclusive de encontrar respostas para as suas inquietações, abrindoIhes novas perspectivas, desvendando formas de resistir [...]". As narrativas são compreendidas, ainda, como práticas sociais e expressões de experiências vividas.

Para iniciar os procedimentos metodológicos, foi feita uma pesquisa bibliográfica para fazer o levantamento de todo referencial teórico a ser utilizado durante a investigação. Além disso, houve uma análise dos documentos referentes a implantação dos cursos de licenciatura nos Institutos Federais (legislação, referenciais, planos de cursos, entre outros).

Como instrumentos de coleta de dados, foi utilizada a entrevista semi-estruturada para detalhar as narrativas dos professores sobre o objeto em estudo. Compreendemos a entrevista como um momento de interação, em que as informações obtidas não são neutras, existindo uma intencionalidade, como afirma Szymanski

[...] a entrevista face a face é fundamentalmente uma situação de interação humana, em que estão em jogo as percepções do outro e de si, expectativas, sentimentos, preconceitos e interpretações para os protagonistas: entrevistador e entrevistado. [...] A intencionalidade do pesquisador vai além da mera busca de informações; pretende criar uma situação de confiabilidade para que o entrevistado se abra (s.n.t., p.12). 
A entrevista realizada foi organizada em três etapas: a primeira etapa tinha como objetivo recolher dados pessoas do sujeito entrevistado, tais como nome completo, idade, entre outros, a segunda etapa busca conhecer a formação e experiências profissionais do entrevistado e a última são questões relacionadas a formação e as práticas que são desenvolvidas dentro do Instituto Federal de Alagoas.

Para a coleta de dados foram investigados $30 \%$ dos professores do eixo específico dos cursos de Licenciatura em Matemática, Ciências Biológicas e química do Instituto Federal de Alagoas- Campus Maceió.

\section{RESULTADOS E DISCUSSÕES}

\subsection{As experiências profissionais dos professores do Instituto Federal de Alagoas}

A construção da identidade dos professores é uma questão muito complexa, considerando a apropriação que cada um faz de suas experiências vividas, de sua história e autonomia diante dos saberes adquiridos ao longo do seu processo formativo.

Nóvoa (2000, p.16) ao afirmar que "a identidade não é um dado adquirido, não é uma propriedade, não é um produto. A identidade é um lugar de lutas e de conflitos, é um espaço de construção de maneiras de ser e de estar na profissão".

Ainda segundo Nóvoa (1992), a construção da identidade docente ocorre a partir de três dimensões: pessoal, profissional e institucional. A dimensão pessoal refere-se aos processos de construção da vida do professor. Na dimensão profissional, são considerados os aspectos da profissionalização docente. Já na dimensão institucional destina-se aos investimentos que a instituição realiza para a obtenção dos seus objetivos educacionais.

Todas essas dimensões se configuram nas posições tomadas pelos professores durante a realização do seu trabalho docente, definindo a sua identidade profissional.

[...] uma identidade profissional se constrói, pois, com base na significação social da profissão; na revisão constante dos significados sociais da profissão; na revisão das tradições. Mas também com base na reafirmação de práticas consagradas culturalmente que permanecem significativas. [...] Constrói-se, também, pelo significado que cada professor, enquanto ator e autor, confere à atividade docente em seu cotidiano, em seu modo de situar-se no mundo, em sua história de vida, em suas representações, em seus saberes, em suas angústias e anseios, no sentido que tem em sua vida o ser professor (PIMENTA, ANASTASIOU, 2002, p.77)

Para melhor compreender a formação dos professores do IFAL iremos caracterizar os professores de acordo com suas formações e suas experiências profissionais. Serão utilizados nomes fictícios de Rogério, Marcos e Rafael para preservar a identidade dos sujeitos analisados.

Rogério tem 51 anos, é casado, natural de Limoeiro de Anadia, um município do interior de Alagoas. A primeira professora de Rogério foi sua própria mãe, a qual foi uma das motivações para a escolha de sua profissão. Quanto a sua formação, estudou em escolas públicas da rede estadual até a $8^{a}$ e no ensino médio ingressou na então escola técnica, atualmente Instituto Federal de Alagoas, e cursou eletrotécnica, por essa razão optou por prestar vestibular para engenharia, onde 
não foi aprovado e no ano seguinte, seguindo o conselho de sua irmã, também professora, prestou vestibular para licenciatura em matemática na Universidade Federal de Alagoas e foi aprovado. Após terminar seu curso de licenciatura, prestou vestibular mais uma vez para engenharia, curso que também concluiu. Mesmo formado em engenharia, $\mathrm{O}$ entrevistado decidiu continuar com sua carreira docente, pois já estava lecionando e escolheu seguir nessa área, por essa razão, decidiu fazer mestrado na área de Educação matemática e hoje é professor com dedicação exclusiva do IFAL, atuando no ensino médio técnico integrado, nos cursos tecnológicos e no curso de licenciatura em matemática.

Marcos tem 38 anos, é casado, natural de Maceió. Em relação a sua formação, possui graduação em Ciências Biológicas pela Universidade Federal de Alagoas, tendo mestrado em química na área de biotecnologia na mesma instituição. Contou que escolheu ser professor por ter afinidade com biologia e gosta de sua profissão. Decidiu ser professor Do Instituto Federal de Alagoas em função da estabilidade financeira e com intuito de agregar novos conhecimentos e ampliar as possibilidades do ensino de pesquisa. O entrevistado já foi professor da rede pública estadual e já lecionou em cursos de nível superior de instituições privadas. Atualmente atua no curso médio integrado e no curso de licenciatura em Ciências Biológicas do IFAL.

Rafael tem 40 anos, casado, nascido em Recife/Pernambuco, durante o ensino médio estudou na Escola técnica Estadual de Pernambuco. Possui graduação em licenciatura em Química pela Universidade Federal Rural de Pernambuco e mestrado e doutorado pela Universidade Federal de Pernambuco. A escolha pela profissão docente ocorreu durante sua graduação, quando o entrevistado relata ingressou no curso de licenciatura pois queria ter um curso superior e após ter contato com a aprendizagem, percebeu que era a profissão que ele queria e gosta de exercela. O entrevistado já trabalhou em escolas particulares e da rede pública municipal e estadual no nível fundamental e médio. Tornou-se professor do IFAL por acaso, quando prestou concurso para o IFPE e foi remanejado para o IFAL. No instituto Federal de Alagoas atua como formador de cursos de formação continuada para professores, onde esses professores trazem suas respectivas realidades dentro de sala de aula e o intuído doo curso é trabalhar em cima dessa realidade dentro das escola desses professores, também é professor dos níveis médio, técnico, superior e pósgraduação do IFAL.

Após a caracterização dos docentes é possível perceber que esses professores acabam se tornando polivalentes, traduzindo uma identidade profissional indefinida, visto que a construção de uma identidade está atrelada ao papel que estes assumem nas instituições de ensino. A polivalência pode ser justificada pelo fato de ser

Uma característica do novo modelo de produção, mais flexível e informatizado, que surge para substituir o taylorismo/fordismo. $O$ aspecto mais relevante deste novo modelo de organização do trabalho é a exigência de o trabalhador desempenhar várias tarefas ou funções dentro do local de trabalho (SANTOS, PIZZI, 2007, p.162).

Essa situação faz com que o trabalho desse docente não possua uma identidade própria, tendo ele que reorganizar a sua prática educativa para atender a toda essa diversidade educacional, que requer estudos e metodologias próprias para cada nível e modalidade de ensino.

Todas essas dimensões se configuram nas posições tomadas pelos professores durante a realização do seu trabalho docente, definindo a sua identidade profissional. 
[...] uma identidade profissional se constrói, pois, com base na significação social da profissão; na revisão constante dos significados sociais da profissão; na revisão das tradições. Mas também com base na reafirmação de práticas consagradas culturalmente que permanecem significativas. [...] Constróise, também, pelo significado que cada professor, enquanto ator e autor, confere à atividade docente em seu cotidiano, em seu modo de situar-se no mundo, em sua história de vida, em suas representações, em seus saberes, em suas angústias e anseios, no sentido que tem em sua vida o ser professor (PIMENTA, ANASTASIOU, 2002, p.77).

Nesse sentido, a identidade do professor passa por um processo constante de revisão dos significados sociais da sua profissionalização.

\subsection{As narrativas docentes e suas práticas}

Para melhor compreender a formação dos professores do IFAL e como o próprio Instituto pode estar colaborando com a continuidade desta para seus próprios docentes, além de caracterizar os professores também foram feitos outros questionamentos para compreender suas respectivas relações com os cursos de licenciatura do IFAL.

Segundo Huberman (1992 apud, Helmer, 2015, p. 45) se a fase de início de carreira for positiva, passa-se a uma fase de estabilização, quando o indivíduo sente que fez a escolha correta e, então, passa a concentrar seus esforços para manter-se nela. É o momento de reconhecer-se como parte de uma cultura que respeita um código de ética e aceita a pirâmide social e de trabalho à qual se está submetido. Nessa fase, a meta é adquirir condições satisfatórias para o desempenho de papéis e responsabilidades cada vez mais importantes e de maior reconhecimento. Para tanto, busca-se pelo domínio técnico e maior especialização na profissão escolhida.

Sendo assim os professores foram questionados sobre o que os motivou a escolher a profissão docente:

Segundo Rogério "Eu acredito que a principal influência foi a minha mãe, mas ao longo da minha eu tive 3 professores que eu digo que marcaram a minha vida e me deram a certeza que eu queria ser professor de matemática, que eu me identificava com aquilo."1

E Ainda Acrescenta:

[...] eu acredito que eu não conseguiria fazer outra coisa, eu não fui um aluno ruim na área da engenharia, mas eu percebi que eu não tenho muita paciência pra fazer aquelas coisas que lá na engenharia elas são muito mecânicas [...], mas mais adiante eu descobri que pra o camarada ser bem sucedido na área da construção civil ele tem que se submeter a algumas questões muito complexas do ponto de vista de até mudar a personalidade pra se dar bem e eu preferi me distanciar disso, mas na realidade algumas coisas que eu aprendi na engenharia civil pra mim foram importantes, porque eu como professor da matemática que na época que eu estudei, na época que eu fiz matemática, fui formado numa concepção muito tradicional, estudar matemática era fazer conta, passei o curso inteiro nunca fiz uma prática, ninguém nunca fez uma discussão sobre um caminho diferente que pudesse nos dar a possibilidade de trabalhar de uma forma até mais atrativa 0

${ }^{1} \mathrm{O}$ texto em itálico foi utilizado para dar ênfase à fala dos entrevistados. 
conteúdo na sala de aula, então eu nunca consegui ver isso, aí depois que eu comecei a ensinar, alguma coisa que eu aprendi na engenharia eu fui começando a relacionar com o conteúdo matemático, porque quem resolve os problemas da engenharia é a matemática e a física, aí foi a partir daí que eu acredito que algum conhecimento que eu aprendi nas engenharias, contribuiu bastante para que eu pudesse na realidade compreender para que a maioria dos conteúdos da matemática,[...]. (Rogério, 51 anos)

De acordo com Rogério, fazer essa associação do cotidiano e os assuntos matemáticos na época em que começou a lecionar além de ser bem complexo para os professores, era uma coisa que quase não se fazia, principalmente por falta de tempo dos professores. Quando questionado sobre a importância de ser professor do IFAL, o mesmo responde que grande parte da sua vida foi dentro do instituto, uma vez que ele já foi aluno da instituição, e hoje se sente grato em poder fazer parte da formação de professores no IFAL.

Rafael diz gostar de sua profissão, e quanto a motivação para a escolha da carreira docente, ele diz que:

A motivação veio durante o curso de licenciatura, quando eu fui fazer o curso eu não queria ser professor, fui fazer o curso por cursar um curso superior, mas durante o curso com as disciplinas que eu fui tendo contato com aprendizagem, aí eu percebi que era a profissão que eu queria. (Rafael, 40 anos)

Marcos, sobre escolha de sua profissão diz:

"Foi uma escolha feita com base na afinidade que sempre tive pela área da Biologia, unicamente."

E ainda acrescenta:

[...]Na verdade, sempre mantive afinidade com a biologia. Ajudava meus colegas de classe nas atividades em sala de aula. Assim que terminei o ensino médio tive a certeza de que a escola seria o lugar onde me sentiria produtivo, criaria vínculos com as pessoas e teria a oportunidade de ver a diferença que essa convivência faz na nossa vida. Acreditava que a Educação escolar transformaria a minha realidade e, consequentemente, poderia transformar a vida de outros alunos também[...] (Marcos,38 anos)

De acordo com Helmer e Reyes:

Aprofundando um pouco mais a questão da profissionalidade docente, Cunha (2007) aponta que o termo tem sido utilizado, indicando se tratar de uma profissão em ação, em processo, em movimento. Gimeno-Sacristán (1999, p. 65) refere-se à profissionalidade como "expressão da especificidade da atuação dos professores na prática, isto é, o conjunto de atuações, destrezas, conhecimentos, atitudes e valores ligados a ela que constituem o específico de ser professor". A profissionalidade, dessa maneira, envolve uma grande diversidade de funções, como: ensinar, orientar, atender os alunos individual ou coletivamente, mediar relações, preparar materiais, avaliar, organizar espaços, dentre outras.( 2015 , p.4)

Dessa forma, os professores foram questionados a respeito do significado em ser professor: 
Pra mim ser professor de matemática num primeiro plano, eu vejo que é uma realização, não só profissional, mas uma realização pessoal, eu vejo as duas coisas, a realização profissional acredito que completa a realização pessoal. Por outro lado eu vejo que ser professor de matemática já num segundo plano, é a gente ter a possibilidade de poder despertar, não só no aluno lá no início da educação infantil, mas de lá até a educação superior, acredito que ser professor é ter a possibilidade de poder despertar a curiosidade das pessoas, daqueles que passam pela sua vida profissional. Quando a gente consegue fazer com que as pessoas despertem pra importância de querer saber a importância daquilo que alguém nunca imaginou que tinha um sentido, eu acredito que essas 3 coisas pra mim são essenciais: a realização profissional, a realização como pessoa e dentro da realização como pessoa é poder despertar a curiosidade de outras pessoas que querem aprender de fato, porque as vezes a gente acha que aprendeu mas na realidade se quer sabe o significado de atender, acredito que essas 3 coisas se complementam. (Rogério, 51 anos)

Ser professor é dar conhecimento e contribuir na sua solidificação; formar ideias e propor desafios; ensinar a escutar e aprender a ouvir; desenvolver métodos e ensinar a praticar ciência; compartilhar experiências e formar bons e éticos profissionais. Além de tudo isso, é imprescindível humanizar o discente para que este não veja apenas um mero aluno na sua prática profissional, mas alguém que tem sede de conhecimento, com suas dificuldades e competências, pois um cidadão deve contribuir de forma ativa, benéfica e positiva, opinando e participando da resolução das questões sociais, a fim de mudar a realidade que o cerca. (Marcos, 38 anos)

Concordamos como Marinho (2015, p.71) "[...] a formação continua de professores assumem um papel importante para a ressignificação da crise de identidade profissional docente.", sendo assim, percebe-se que os docentes dos cursos de licenciatura necessitam estar em processos de aprendizagem contínuos que auxiliem na tanto em suas áreas especificas de ensino, quanto em suas práticas docentes, para que os mesmos consigam alcançar as melhores maneiras de formar um professor, por esse motivo os docentes foram questionados a respeito dos possíveis cursos de formação continuada realizados por eles para saber se estes proporcionaram melhoria em suas práticas pedagógicas enquanto professores das licenciaturas:

Eu vou dizer o IFAL em função de que o IFAL é um curso de licenciatura. Acredito que se aqui não tivesse chegado o curso de licenciatura, eu teria estacionado, tenho quase certeza disso, porque caso não tivesse chegado eu estaria dando aula só na educação básica, e você chega em um momento que aquilo se torna tão repetitivo que você nem se quer para planejar uma aula porque você domina o conteúdo quase sem precisar organizar uma aula. Com a chegada da licenciatura, eu senti a necessidade de não só me atualizar ainda mais, mas me senti no compromisso de contribuir para que a licenciatura pudesse ser trabalhada numa concepção de ensino um pouquinho diferente daquela concepção tradicional na qual eu fui formado, aí eu sempre digo aos meus alunos da licenciatura "se nós fizermos um pesquisa com todos os professores que se formaram antes de mim, todos eles se perguntarem sobre metodologia, ele só vão dizer assim 'aula expositiva'" e é tudo assim, aula expositiva e assim por diante. (Rogério, 51 anos) 
"Referindo-se a cursos de formação, não existem muitas contribuições. No entanto, é inegável a aquisição de novos conhecimentos e a experiência na prática docente." (Marcos, 38 anos)

E ainda acrescenta:

[...] No Instituto Federal de Alagoas existe uma política de formação e qualificação dos seus profissionais, mas ainda como uma prática voltada para determinadas formações. [...]

Rafael quando questionado se o IFAL contribui para seu processo formativo enquanto professor, ele responde que sim, e inclusive o mesmo participa de cursos de formação continuada na instituição, tanto como ouvinte ou ministrando os cursos.

É possível perceber que os docentes reconhecem a necessidade de participar de cursos de formação continuada, alguns destes cursos, segundo os próprios docentes são ofertados pela própria instituição de ensino, visto que o IFAL ainda é muito recente, compreende-se a necessidade de melhor formar esses professores que antes não estavam habituados a lidar com formação de professores, sendo assim os professores foram questionados se eles se sentem preparados para lecionar no ensino superior, após a chegada dos cursos de licenciatura no IFAL, e temos como respostas:

Me sinto, todas as disciplinas não, eu me formei em matemática em 88 algumas disciplinas na época que eu me formei elas foram muito mal ministradas pelos professores porque os professores não dominavam e eu confesso que algumas delas eu não aprendi,[...] (Rogério, 51 anos)

Sinto-me preparado, considerando minha formação profissional e vivência nas disciplinas lecionadas. No entanto, a instituição não fornece condições apropriadas para o desempenho adequado das minhas disciplinas como livros didáticos específicos; salas de estudo para docentes e discentes; laboratório para atividades práticas do curso; aparelhos multimídia e materiais outros para desenvolver atividades diversas pertinentes ao curso[...] ( Marcos, 38 anos)

Os professores relatalatam que o diferencial de trabalhar no Instituto Federal é o fato de poder trabalhar em diferentes níveis e modalidades de ensino em uma única instituição, fator esse que pode ser bom por um lado, porém pode ser um fator complicador em relação as práticas pedagógicas utilizadas pelos professores nas diferentes modalidades, por esse motivo, os docentes entrevistados foram questionados se há uma diferença entre a pedagógica para ensinar no curso de Licenciatura e em outros cursos/níveis/modalidades de ensino no IFAL e eles dizem que:

[...],quando a gente tá trabalhando num curso da licenciatura, a gente tem que perceber que o aluno se espelha na gente como professor então é diferente algumas posturas que temos que ter no curso de licenciatura é uma postura um pouco diferente da postura que temos em outros cursos, então por exemplo, não que em outras modalidades não haja mas na licenciatura tem que se levar em conta a interação com o aluno da licenciatura, então o professor ele não pode ficar muito distante do aluno, tem que na sua prática esse ponto ele tem que tentar colocar que é uma interação próxima com o aluno. (Rafael,40 anos)

Com relação a sentir preparado para formar professores afirma: 
Sim, eu já faço isso, porque é... Primeiro por que eu já conheço, assim nossa aqui por exemplo de só conhecer a educação básica, e eu já tenho essa experiência há algum tempo de contribuir pra melhor formação do professor, a gente sabe das dificuldades que eles tem na escola, então a partir dessas dificuldades que eu já conheço, aí a gente prepara um plano de curso que passa direcionar ele pra atuar diretamente lá na escola dele. (Rafael, 40 anos)

Marcos relata que em relação a sua prática pedagógica ele diz que há uma diferença entre a metodologia na educação básica e ensinar em um curso de licenciatura, visto que as diferentes modalidades pedem práticas de ensino também diferentes, considerando o conteúdo ensinado, a forma de abordagem, o objetivo do curso e o público-alvo que constitui o curso. Marcos também relata que sua experiência como professor da rede pública estadual de educação, ministrando aulas para turmas de educação básica facilitou sua atuação em um curso de licenciatura. 0 discente afirma que o Instituto Federal de Alagoas forma professores para atuarem na educação básica, mesmo considerando as dificuldades e faltas existentes no curso. Ainda sim, os docentes preparam os discentes para esta formação tão importante dos jovens. No entanto, a experiência que ele vivencia durantes esses anos de ensino mostra que parte do sucesso desta formação se deve a participação efetiva dos discentes nas atividades do curso, sejam elas teóricas, experimentais ou de pesquisa.

Rogério afirma que em sua prática pedagógica existe uma diferença entre sua metodologia para ensinar na educação básica e para ensinar em um curso de licenciatura, e isso o faz sentir-se preparado para ser um professor formador de professor. Rogério também diz que sua experiência na educação básica facilita sua atuação em um curso de licenciatura, uma vez que o mesmo sabe o que é vivenciar uma turma de educação básica. Em sua opinião, o IFAL está no caminho para formar professores, que mesmo ainda precisando ter avanços, o aluno que se forma já tem uma noção do que ele pode encontrar em sala de aula e de como abordar certos conteúdos, coisa que não acontece com licenciandos de outras instituições que ainda possuem uma formação de professor com características de bacharel.

Concordamos com Houssaye(1995) e Pimenta (1996a, apud Pimenta 1997,p.6)quando diz que "É nesse contexto que as pesquisas sobre a prática, estão anunciando novos caminhos para a formação docente. Um deles, refere-se à discussão sobre a identidade profissional do professor, tendo como um de seus aspectos a questão dos saberes que configuram a docência."

Dessa forma, a partir das entrevitas realizadas com os docentes é possível perceber que, como os cursos superiores são recentes nos IF`s, e os professores que já atuam no nível técnico passam a se adaptar a essa nova realidade, que o trabalho docente não possui uma identidade própria, tendo ele que reogarnizar a sua prática docente para atender a toda essa diversidade educacional, que requer estudos e metodologias próprias para cada nível e modalidade de ensino, além de possibilitarem perceber as concepções e perspectivas da formação de professores nos cursos de licenciatura oferecidos pelos Institutos Federais como uma oportunidade para os mesmo se qualificarem.

Isso nos permite afirmar que a docência é uma atividade profissional complexa, que demanda saberes diversificados e, por isso, é preciso discutir cada vez mais a questão da identidade profissional docente. 


\section{CONCLUSÃO}

Assim sendo, a formação inicial não pressupõe apenas uma formação de carácter acadêmico e disciplinar, como possui igualmente uma formação que pretende dar resposta às novas demandas de atuação do professor como um dos agentes sociais mais ativos das mudanças. Justifica-se pela necessidade de uma qualificação profissional para o exercício da função docente, devendo estar, no entanto, adequada às exigências educativas e de ensino - aprendizagem dos educandos nos vários níveis de ensino.

Após a análise das entrevistas, foi possível notar que os professores que atuam nos cursos de licenciatura do IFAL estão em processo de construção de suas respectivas identidades profissionais, bem como a própria instituição encontra-se no mesmo processo, uma vez que estes foram impostos a tais mudanças, independente da característica da instituição ou da formação dos docentes. Com isso, percebe-se a necessidade de uma melhora no processo formativo desses e uma adaptação de suas práticas pedagógicas, para que estes estejam aptos a formar novos professores.

A formação assume-se como um processo pelo meio o qual, o docente aprende e desenvolve habilidades inerentes à sua prática. Nesta perspectiva, a formação do professor deve ser vista não só como uma habilitação para qualificá-lo como um profissional, mas como o desenvolvimento de ações que propiciem ao mesmo tempo, uma constante retomada dos conhecimentos específicos com os quais trabalha, dando a possibilidade de reflexões em torno da sua prática.

Apesar de existirem diferentes concepções sobre as fases ou etapas do processo de formação de professor, podemos dizer que qualquer formação deve ser permanentemente inovada, tendo em conta a evolução dos saberes, das tecnologias e da sociedade.

\section{REFERÊNCIAS}

1. CHIZZOTTI, A. Pesquisa em ciências humanas e sociais. São Paulo: Cortez, 2001 educação: questões contemporâneas. Maceió: EDUFAL, 2007, p.161-174.

2. GUEDES-PINTO, A. L. Rememorando trajetórias da professora-alfabetizadora: a leitura como prática constitutiva de sua identidade e formação profissionais. Campinas, SP: Mercado de Letras, 2002

3. HELMER, E. A. Elementos constitutivos da aprendizagem docente no Instituto Federal de Educação, Ciência e Tecnologia de São Paulo. Sinergia. São Paulo, v.16, n.1,p.46-50,2015.

4. HELMER, E. A.;REYES, C. R. Elementos constitutivos do desenvolvimento profissional da docência no Instituto Federal de Educação, Ciência e Tecnologia de São Paulo,2015.

5. LIMA, F. B. G. de; SILVA, K. A. C. P. C. da. As licenciaturas nos institutos federais: concepções e pressupostos. 2011. Disponível em: <http://www.ceped.ueg.br/anais/ivedipe/pafs/dida tica/co/40-164-2- SP.pdf>. Acesso em: 01 fev. 2015

6. Lei no 11.892, de 29 de dezembro de 2008. Institui a Rede Federal de Educação Profissional, Científica e Tecnológica, cria os Institutos Federais de Educação, Ciência e Tecnologia, e dá outras providências. Brasília, 2008. Disponível em: <http://www.planalto.gov.br/ccivil_03/ _Ato2007- 2010/2008/Lei/L11892 .htm>. Acesso em: 01 fev. 2015 
7. MARINHO, P. Identidades profissionais docentes- na "desordem" construindo uma "nova ordem". Revista Brasileira de Educação de Jovens e Adultos, v.3, n.5, p. 60-75,2015.

8. NÓVOA, A. Diz-me como ensinas, dir-te-ei quem és e vice-versa. In: FAZENDA, I. (org.). A pesquisa em educação e as transformações do conhecimento. 2.ed. Campinas: Papirus, 1997.

9. PIMENTA, S. G.; ANASTASIOU, L. das G. Docência no ensino superior. São Paulo: Cortez, 2002.

10. PIMENTA, S. G. Formação de Professores- saberes da docência e identidade do professor.Nuances, vol III p.5-14, 1997

11. SANTOS, R. M. B.; PIZZI, L. C. V. A polivalência do trabalho docente hoje. In: PINTO, A. de C.; COSTA, C. J. de S. A.; HADDAD, L. (orgs.). Formação do pesquisador em educação: questões contemporâneas. Maceió: EDUFAL, 2007, p.161-174.

12. SZYMANSKI, H. A entrevista na pesquisa em educação: a prática reflexiva. s.n.t. 